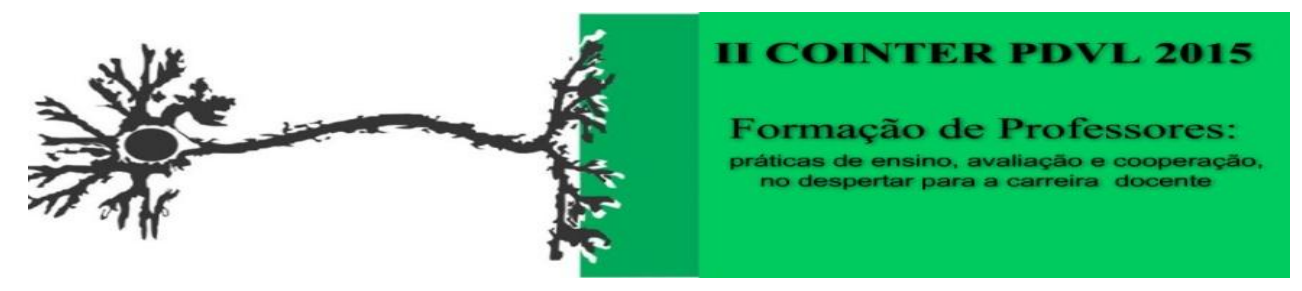

\title{
A LICENCIATURA EM GEOGRAFIA NO IFPE CAMPUS RECIFE (BRASIL) E DE PROFESSORADO NA UNLP (ARGENTINA), FRENTE À QUESTÃO DO DESINTERESSE PELA CARREIRA DOCENTE
}

\author{
Apresentação: Comunicação Oral \\ GUERRA JUNIOR, Alessandro Augusto ${ }^{1}$; AZEVÊDO, Matheus Souto Mendes de ${ }^{2}$; \\ BARBOSA, Adauto Gomes ${ }^{3}$
}

\begin{abstract}
Resumo
Com base nas ações do PIBEX, o artigo faz uma breve análise da inserção dos estudantes do curso de licenciatura/professorado em Geografia no IFPE, no Brasil, e na UNLP, na Argentina, considerando as circunstâncias que os motivaram pela escolha de curso de formação de professor. Parte-se do reconhecimento das dificuldades atuais que se impõem à carreira do magistério, a qual, desprestigiada econômica e socialmente, desestimula muitos concluintes do Ensino Básico ou Secundário a concorrerem a vagas ou ingressarem em cursos de formação docente em ambos os países. Além disso, muitos do que ingressam desistem logo nos primeiros anos ou períodos, o que agrava sobremaneira o problema da falta de professor, inclusive na área de Geografia. Diante disso, o artigo faz um diagnóstico com os estudantes quanto os motivos da escolha pela carreira docente e em que desafios se inserem os estudantes do curso de Geografia em duas instituições de formação de professores, em dois países, que ensejará um conjunto de reflexões teóricas em buscar compreender os motivos pela carreira do magistério. Nas duas realidades investigadas, constatou-se que a maior parte dos estudantes que permanece no curso tem interesse em seguir a carreira docente e/ou de seguir carreira acadêmica por meio da pós-graduação.
\end{abstract}

Palavras-chave: Licenciatura em Geografia do IFPE Campus Recife, Curso de Professorado em Geografia na UNLP; Interesse pela carreira docente.

\section{Introdução}

O presente artigo se insere no plano de trabalho do Programa Despertando Vocações para a Licenciatura: diálogos e possibilidades metodológicas do Ensino de Geografia, concebido e desenvolvido no âmbito do Instituto Federal de Pernambuco (IFPE), tendo atualmente alcance em outras Instituições de Educação Superior a nível internacional. O artigo teve com base na experiência dos estudantes no Programa de Extensão do IFPE (PIBEX) e na participação de Mobilidade Estudantil internacional na Universidade Nacional de La Plata (UNLP), na Argentina. Esse programa foi elaborado com base na problemática relacionada com o baixo nível de interesse pelas licenciaturas por parte dos estudantes aspirantes aos cursos superiores. Soma-se a isso a alta evasão que ocorre nos cursos de formação de professor, contexto em que as licenciaturas em

\footnotetext{
${ }^{1}$ Estudante da Licenciatura em Geografia do IFPE, Campus Recife, augguerra@gmail.com

${ }^{2}$ Estudante da Licenciatura em Geografia do IFPE, Campus Recife, azevedomatheus83@gmail.com

${ }^{3}$ Professor da Licenciatura em Geografia do IFPE, Campus Recife, adauto@ recife.ifpe.edu.br
} 
Geografia figuram entre os principais casos de manifestação desse problema.

Algumas pesquisas que tratam a respeito da profissão docente têm demonstrado que a cada ano diminui, de forma significativa, o interesse pelos cursos de licenciaturas dos estudantes aspirantes à Educação Superior, ocasionando uma crise nesses cursos e principalmente na carreira docente, em decorrência da falta de professores devidamente habilitados para o exercício do magistério.

A propósito, "Os dados do INEP (Instituto Nacional de Estudos e Pesquisas Educacionais Anísio Teixeira), mesmo que preliminares, apontam para uma necessidade de cerca de 235 mil professores para o Ensino Médio no país, particularmente nas disciplinas de Física, Química, Matemática e Biologia” (BRASIL, 2007, p. 11). Além desse grave problema da escassez, o mesmo documento também ressalta que “[...] os cursos de licenciatura têm uma elevada taxa de evasão, chegando a 75\% em Química e 47\% em Geografia" (idem).

Na Argentina o cenário é semelhante, segundo Mezzadra (2014) existe um desequilíbrio entre a quantidade e o tipo da especialidade dos docentes com a necessidade do sistema educativo. Ou seja, faltam professores das disciplinas específicas nas escolas, principalmente as do ciclo secundário, o qual corresponde as séries do ensino médio no Brasil. De acordo com a mesma autora, em 2004, 7\% dos docentes em atuação se encontravam fora da área de formação, já no ciclo secundário, esta proporção crescia, atingindo os $13 \%$ em todo país. Quando equipara com região mais populosa do país, a proporção ascendia para 27\% na área metropolitana de Buenos Aires e 31\% na capital do país, a Cidade Autônoma de Buenos Aires. Segundo Zamero, (2010) é comum encontrar professores ou maestros de nível primário ensinando no nível secundário e professores do secundário no nível primário, como também professores das disciplinas de humana, ensinando as das ciências exatas ou naturais.

Dessa forma, o desafio não consiste apenas na escassez de professores e em atrair estudantes para a Educação Superior com alto interesse pela licenciatura/professorado, mas, também, mantêlos até o término de seus respectivos cursos. No caso da Licenciatura em Geografia do IFPE, campus Recife, por exemplo, a evasão supera $50 \%$ das vagas ofertadas, sem que na virada do segundo para o terceiro período, ou seja, após concluir o primeiro dos quatro anos do curso, tal problema alcança metade das vagas inicialmente preenchidas ${ }^{4}$. No curso de Professorado ${ }^{5}$ em Geografia na UNLP, dos 41 que ingressam anualmente, ao longo dos cinco anos de curso, boa parte

\footnotetext{
${ }^{4}$ Embora esse não seja exatamente o foco dessa discussão, a evasão é muito elevada também em outros cursos superiores e alguns estudantes da Licenciatura em Geografia em contexto têm alegado que com o SISU ficou mais fácil ingressar nos cursos superiores e daí mal começarem um curso, o evadem para fazer outros, o que, no caso da Licenciatura mais uma vez corrobora certo desinteresse pela carreira docente.

${ }^{5}$ Curso de formação de professores, equivalente aos cursos de licenciaturas no Brasil.
} 
acaba seguindo para o bacharel ou simplesmente desistem. Desse modo, há um afunilamento ao longo dos cursos, o qual é muito preocupante.

A experiência empírica e a produção de estudos e pesquisas a respeito da carreira docente têm demonstrado que, ao longo dos anos, não tem sido do interesse dos jovens a escolha da profissão de professor. É válido destacar que muitos defendem que a opção pela carreira docente é, muitas vezes, expressão da falta de alternativas mais interessantes em termos econômicos, já que a insatisfação docente é algo muito presente no contexto escolar. Além dos baixos salários pagos nessa área, há ainda problemas decorrentes da falta de uma boa relação com os estudantes, onde até mesmo ameaças e violência física se impõem como parte da realidade. Por sua vez, há ainda um forte desinteresse e fracas perspectivas pelos estudantes da rede pública em relação às possibilidades de ingressar na Educação Superior na Argentina e de aprovados nos processos seletivos no Brasil. Em paralelo a isso, numa realidade em que imperam os valores do individualismo e da sociedade de consumo, são valorizadas as carreiras que proporcionam maiores ganhos financeiros ou que estejam ligadas às atividades mais em expansão no mundo do trabalho.

A UNLP como uma das maiores universidades da Argentina e da América do Sul, com 110 anos de existência e com mais de 100 mil estudantes matriculados, vem desde 1914, com a criação da Facultad de Ciencias de la Educación contribuindo na formação de professores. Seus primeiros cursos foram voltados para formação de professores, principalmente para nível universitário e para as escolas públicas vinculadas à própria universidade (Colegio Nacional, Escuela Normal e Escuela Graduada Anexa). A partir de 1920, com criação da Facultad de Humanidades y Ciencias de la Educación (FAHCE), possibilitou unir os cursos da área da ciências humanas com os cursos de educação, viabilizando uma maior de integração, discussão e dialogo na formação na área específica com os conteúdos pedagógicos, oferecendo uma formação de graduação e pós-graduação. Apesar de toda a tradição na formação de professores, a UNLP tem muitos desafios a superar, principalmente de atrair e formar docente.

O IFPE é muito recente neste cenário na formação docente, que ao longo dos seus 106 anos se destacou o seu papel estratégico de ofertar cursos para educação técnica profissional no nível médio do Ensino Básico, onde só a partir de 2008, com a nova institucionalização, que equiparou os Institutos Federais às universidades, em paralelo à criação e à expansão dos cursos de graduação, como as licenciaturas. De acordo com a Lei 11.892/2008, ficou estabelecido que os Institutos Federais de Educação, Ciência e Tecnologia deveriam garantir $20 \%$ de suas matrículas às licenciaturas, demarcando como um dos focos a formação de professor. Evidencia-se assim, a tarefa do IFPE com a formação de professores para a educação básica no estado de Pernambuco, no contexto problemático de escassez de professores não apenas nas ciências exatas e da natureza, 
como também em Geografia, onde é notória a escassez de docentes nas redes municipais e estadual.

É oportuno observar e correlacionar também com o estudo de GATTI (2009), que revelou o crescimento dos cursos de licenciaturas no Brasil, porém o número de inscritos não acompanha esse processo de crescimento. Essa dificuldade, mais uma vez, está aliada ao problema da escassez de professores, principalmente no Ensino Médio, apontado nos dados apresentados no Relatório produzido pela Comissão Especial instituída para estudar medidas que visem a superar o déficit docente no ensino médio (2007) que sinalizam desafios para os cursos. Na Argentina, a quantidade de estudantes ingressos nos Institutos Nacionales de Formación Docente (ISFD), que pertencem aos governos provinciais para formar professores, entre 2005 e 2014 cresceu 23\%. Porém este aumento não se deu de forma uniforme em todas as províncias e tampouco se reflete no número de concluintes, que continua insuficiente a demanda da sociedade (MEZZADRA, 2014).

Dessa maneira, levantar um diagnóstico dos estudantes dos cursos de Licenciatura e Professorado em Geografia no IFPE e na UNLP, respectivamente, considerando as circunstâncias que motivaram pela escolha é propor uma reflexão sobre duas instituições de ensino superior, com suas particularidades, com realidades sociais extremamente distintas, em países muito diferentes que compartilham problema concreto, o de atrair estudantes para formar professores.

\section{Fundamentação Teórica}

A problemática referente ao desinteresse dos estudantes à Educação Superior exige pensar o mundo e suas contradições, numa realidade cada vez mais dominada pelo universo do indivíduo com suas necessidades imediatas ligadas ao consumo de bens materiais. Nesse sentido, impõe-se buscar em novos caminhos, pois, afinal de contas, conforme bem diz Santos (2004), a globalização também pode e, sobretudo, deve ser vista enquanto possibilidade de buscar transformar a realidade como ela deveria ser. Muitos são os meios e recursos disponíveis hoje em dia como recursos didáticos e, não obstante eles, por si só, não tenham qualquer significado maior em termos de transformação da precária situação do Ensino, se bem usados, podem ser importantes instrumentos na construção do processo do conhecimento escolar e no despertar para uma consciência crítica de mundo.

Nesse quadro de referência, concorda-se aqui com o que está posto na justificativa do PDVL, segundo a qual o desinteresse pelos cursos de formação de professores é tanto atrelado aos baixos salários pagos aos profissionais da Educação, quanto se relaciona com o contexto social, cultural e econômico do mundo atual, cada vez mais marcado pelos valores da cultura-mundo (LIPOVETSKY, 2012). De acordo com esse autor, a cultura-mundo se coaduna com a perspectiva de hiperrealidade, em que prevalecem o individualismo e o consumismo, cuja ação indutora é 
protagonizada pelos agentes do mercado que se somam ao papel da mídia, com suas estratégias de marketing, e cada vez mais atrela a felicidade à realização individual, permeada pelo consumo de bens materiais. Sendo assim, ter sucesso profissional significa ser bem remunerado e participar efetivamente da sociedade de consumo.

Dessa maneira, não parece atraente buscar a realização pessoal por meio da carreira profissional docente, a qual é cada vez menos valorizada, quer no plano social, quer economicamente, sendo isto um enorme desafio para quem defende e se compromete com a Educação com vistas à construção de um projeto de sociedade pautada em valores essencialmente humanistas e cidadãos. Em outros termos, muitos dos estudantes da Educação Básica na rede pública se sentem ou de fato são autênticos exemplos de outsiders, nos termos discutidos por Elias \& Scotson (2000). Esse mundo contraditório e dual se revela perverso o bastante para que até mesmo a escolha das profissões seja balizada quase que unicamente pelos valores do mercado e lastreado pela sociedade de consumo.

Mezzadra (2014) aponta diversas pesquisas que reforçam que o baixo salário em comparação a outras profissões que possuem a mesma exigência acadêmica, desmotiva e se apresentam pouco atrativas para aqueles que pretendem seguir a carreira docente. A mesma autora aponta que em vários países, principalmente com um grande desenvolvimento econômico, a profissão docente oferece vantagem, chegando superar as carreiras imposta pela sociedade.

Desse modo, colocando-se como hiperrealidade (LIPOVETSKY, 2012), o atual período é marcado por uma globalização perversa, a qual é apresentada pela mídia e pelos seus vetores hegemônicos como uma grande fábula (SANTOS, 2004). Os valores do consumismo se impõem com todo seu esplendor e as carreiras que não são ou não se mostram recompensadoras financeiramente se tornam pouco atrativas para estudantes que chegam ao final do Ensino Médio ou Secundário.

\section{Metodologia}

É no âmbito dessa problemática discutida aqui que inscrevemos nossas ações. Assim, por meio da mobilidade internacional dos estudantes envolvidos na construção deste artigo, buscou-se captar a realidade das duas instituições públicas de Educação Superior envolvidas, no Brasil e na Argentina, e com base nisso estabelecer um diálogo fecundo entro os cursos quanto à escassez de professores e, mais do que isso, o crescente desinteresse pela carreira docente.

$\mathrm{O}$ trabalho faz uma abordagem qualitativa que se caracteriza pelo enfoque descritivo e interpretativo. Para tanto, apoia-se numa breve apresentação de dados quantitativos que servem de subsídio para a apreciação da realidade em contexto. O campo de investigação foi constituído por 
estudantes do curso de Licenciatura em Geografia do IFPE Campus Recife, no Brasil, e do curso de Professorado em Geografia na UNLP, na cidade de La Plata, capital da província de Buenos Aires, Argentina. Foram consultados, aleatoriamente, dezesseis (16) estudantes de ambos os cursos, via email, sendo oito (08) estudantes do IFPE e oito (08) da UNLP, durante o mês de novembro de 2015. Este instrumento ajudou a levantar alguns dados quantitativos e informações para a construção de um breve diagnóstico sobre os motivos e circunstâncias que o levaram a optar pelo curso e a carreira docente, buscando apreender também suas expectativas quanto à carreira docente.

De posse das respostas dos estudantes, foi feita a análise e interpretação dos dados, buscando identificar o por quê da escolha de seus respectivos cursos, como encaram hoje essa escolha e se pretendem seguir a carreira docente. Também se perguntou quantos já têm curso superior para se verificar se isso teria alguma relação pela opção pelo respectivo curso de formação docente escolhido. A apreciação dos dados é feita no item a seguir.

\section{Resultados e Discussão}

No que diz a respeito à faixa etária, os dados denotaram que $62 \%$ dos estudantes participantes de Geografia do IFPE estão entre 17 e 20 anos; 12,5\% possuem menos de 17 anos; $12,5 \%$ entre 21 e 25 anos; $12,5 \%$ entre 31 e 35 . Entre os oito (8) estudantes participantes da UNLP os dados se assemelham, 62,5\% estão entre 21 e 25 anos e 37,5\% entre 17 e 20 anos. Ficou evidenciada uma diferença entre as faixas etárias entre os estudantes participantes da pesquisa em ambos os cursos, sendo os do IFPE com maior variante.

No tocante a tudo isso, ficou perceptível um perfil jovem, pois a maior parte dos estudantes entrevistados está na faixa de 21 e 25 anos, o que podemos deduzir que os dezesseis (16) estudantes dos cursos de licenciatura/professorado em Geografia, fazem parte um grupo que está preocupado na construção de uma carreira profissional, mesmo com todo desprestígio social construído em torno da profissão docente, em meio ao que Lipovetsky (2012) chama de sociedade marcada pelos valores da cultura-mundo, centrada no individualismo e no consumo de massa, onde mais vale a profissão que propiciar ou menos criar alguma expectativa de enriquecimento financeiro.

Uma das mais importantes e difíceis escolhas que se faz ao longo da vida é sem dúvida a escolha profissional. É sabido que várias razões acabam por direcionar a escolha, dentre elas podem-se ser apontadas a influência da família, o salário, a inserção do mundo do trabalho, o prestígio social, dentre outras. Como tem sido discutido, a carreira docente a priori está longe de ser a mais atrativa do ponto de vista mercadológico. Desse modo, quando perguntados sobre qual seria o motivo determinante para a escolha do curso de licenciatura/professorado em Geografia, 50\% dos oito (8) estudantes de Geografia do IFPE responderam pelo fato de gostar da Geografia; $25 \%$ 
responderam a inserção do mercado de trabalho, 12,5\% apontaram a influência do seu professor da escola para a escolha e também 12,5\% apontaram outros motivos. Não obstante não se possa, a princípio, extrair conclusões estatísticas com base num questionário aplicado aleatoriamente, ainda assim, os resultados obtidos dão uma boa pista acerca das percepções e motivos dos estudantes pesquisados acerca dos dois cursos e dos estudantes.

Por sua vez, os dados do cadastro de matrícula do IFPE, recentemente divulgados pela Comissão Própria de Avaliação (IFPE, 2015), revelam que aproximadamente $70 \%$ do total de estudantes matriculados no curso de Licenciatura em Geografia têm renda familiar de até dois salários mínimos. Isso mostra de forma bem evidente que o estudante do curso tem perfil socioeconômico humilde, sendo a forte evasão inicial também uma decorrência da necessidade de conciliar o trabalho como estratégia primeira de sobrevivência. Realidade semelhante se aplica aos cursos de formação de professor de outras instituições de ensino. Nesse sentido, ressalta-se o perfil "proletário" do curso, o que, sob um olhar cidadão mostra o quão importante é o seu papel na transformação da realidade social na medida em que propicia formação superior de qualidade para quem realmente precisa.

Entre os estudantes entrevistados da UNLP 62,5\% responderem por gostar da Geografia como determinante para a escolha; $12,5 \%$ a inserção do mercado de trabalho, $12,5 \%$ influência do professor da escola; e 12,5\% a valorização profissional. Mesmo com uma sociedade midiática atrelada valores do consumismo que acabam impondo carreiras mais compensatórias financeiramente e de prestigio social apontada por Santos (2004), no tocante, podemos destacar o motivo pelo gosto pela disciplina e a inserção no mercado de trabalho como determinantes na escolha pelo curso dentre os estudantes participantes. Que certa forma, os estudantes buscaram no curso uma ascensão social com algo que identificam e que gostam, não levando em conta o retorno financeiro da profissão.

Quando perguntados se existia algum professor em sua família, 87,5\% dos estudantes participantes de Geografia do IFPE responderam que não, enquanto 12,5\% responderam sim. Dentre os oito (8) estudantes da UNLP os dados foram inversos, $75 \%$ responderam sim e $25 \%$ não. Correlacionando com a pergunta anterior, onde se perguntava o principal motivo pela escolha do curso de licenciatura/professorado em Geografia, o quesito influência familiar não foi optado por nenhum dos estudantes participantes. Porém, não podemos descartar a importância e influência de um professor na família, principalmente entre os estudantes argentinos, diante o papel humanizador e transformador da educação na sociedade. 
Perguntou-se também se os estudantes já possuíam algum curso de graduação concluído e qual seria esse curso. Tanto os estudantes entrevistados do IFPE quanto da UNLP 100\% responderam não.

Seguir a profissão docente ao final do curso é um grande e importante desafio para a universidade e sociedade, visto que, não basta atrair estudantes para os cursos, tampouco formá-los e habilitá-los à docência, se os mesmos não queiram lecionar e seguir a carreira do magistério. Quando indagados se pretendem seguir a carreira docente ao final do curso, dentre os estudantes entrevistados de Geografia IFPE na sua maioria (62,5\%) responderam que sim; outros $25 \%$ responderam talvez; e 12,5\% responderam que não pretendem ser professor de Geografia. Dentre os oito (8) estudantes da UNLP, $75 \%$ responderem sim e $25 \%$ talvez.

Diante os dados, ainda que a amostra utilizada em rigor não possibilite extrair conclusões definitivas em relação ao universo dos estudantes entrevistados de ambos os cursos, ainda assim é possível observar que a maioria dos estudantes, mesmo com todos os desafios da educação em ambos os países, pretendem seguir na carreira docente e ser professor. Embora alguns estudantes tenham respondido talvez, pode-se inferir que, de forma geral há uma postura afirmativa dentre os que os estudantes pesquisados, pois estão no curso de formação docente e pretendem ao concluir seguir na carreira.

Com relação à continuidade da formação acadêmica, em nível de pós-graduação, seja especialização, mestrado ou doutorado, não especificando a escolha pela área específica, podendo ser pela educação ou não, 100\% dos oito (8) estudantes entrevistados de Geografia do IFPE responderam sim, isto é, que pretendem seguir na formação continuada. Já os (8) oito estudantes de Geografia da UNLP os dados ficou equilibrado, 50\% responderam querer seguir para uma pósgraduação e outros 50\% responderam não saber ou talvez. Não obstante o caráter preliminar da presente análise, considera-se razoável depreender que a despeito da elevada evasão constatada no IFPE, os estudantes que continuam o curso o fazem por se identificarem com o mesmo ou de verem nele a possibilidade de crescimento profissional.

Esse dado é muito positivo e em certo sentido está relacionado com o fato de grande parte deles, sobretudo os que não têm vínculo empregatício, ser hoje integrante de programas institucionais de iniciação científica, iniciação à docência e de extensão. Além disso, tendo em vista a recente ampliação da Educação Superior do IFPE e, sobretudo, da Licenciatura em Geografia no campus Recife ter apenas quatro anos de implantação (e de ser a única em funcionamento neste campus), há um esforço dos que a fazem em possibilitar ações permanentes que gerem a reflexão acadêmica por meio da realização de eventos como ciclos de debate, seminário interdisciplinar, realização de aulas de campo e incentivo a participação em eventos externos ao IFPE. 


\section{Considerações finais}

A primeira consideração a se fazer aqui é o enorme desafio de se buscar estabelecer algum nível de comparação com a realidade dos dois cursos ressaltados neste artigo, tendo em vista as muitas diferenças que há no sistema educacional, para não dizer da sociedade brasileira e argentina. Mesmo assim, foi possível observar algumas semelhanças nos dois contextos empíricos analisados. Uma dela diz respeito ao desafio referente ao baixo interesse pela carreira docente, sendo isso materializado pelo que se constata em ambos os contextos pesquisados. Apesar da relativa semelhança socioeconômica dos estudantes licenciandos/professorandos e das diferenças que não são apenas socioculturais, visto se tratar de duas sociedades nacionais muito distintas entre si, há também diferenças quanto à própria estruturação do ensino superior. No Brasil, os cursos de licenciatura em geral têm quatro anos de duração, ao passo que na Argentina são cinco anos. Para além desses elementos, o (des)interesse pela carreira docente se apresenta mais ou menos no mesmo patamar, visto a realidade de (des)valorização do professor em ambos os países parece se apresentar nos mesmos patamares.

Diante disso, o perfil dos estudantes considerando as circunstâncias que motivaram pela escolha dos cursos de licenciatura/professorado em Geografia fala muito sobre as duas realidades, em países diferentes que compartilham de problemas em certo sentido comuns. De uma forma geral, os estudantes buscam a ascensão social e melhoria do atual padrão de vida e também veem na carreira docente uma possibilidade para tal propósito profissional. Na sua maioria são jovens, entre 21 a 25, que ingressaram no curso por gostar da Geografia, que pretendem seguir a carreira docente e continuar em formação em nível de pós-graduação. Isso de algum modo atesta que ao menos no caso do IFPE, os estudantes que continuam no curso demonstram interesse em não só concluir o curso, como ainda fazer pós-graduação e investir na sua formação acadêmica.

É preciso considerar, que diante da problemática referente ao desinteresse dos estudantes pela carreira docente atrelado ao desafio que consiste a escassez de professores e manter os estudantes ao longo do curso, compreender os motivos que o levaram a optarem e cursarem a licenciatura/professorado em Geografia é de fundamental importância, pois eles serão os futuros professores da educação básica do Brasil ou Argentina. Como desdobramento da breve reflexão aqui ensejada, há a necessidade de se voltar para a análise das políticas públicas em ambos os países, com o fito de verificar de que maneira a questão da formação docente vem sendo efetivamente diligenciada. Isso, sem dúvida, dependendo do que ou como esteja sendo efetivado, opera a favor ou contra o reconhecimento do profissional docente e, por conseguinte, põe em xeque o papel dos cursos de licenciatura e de professorado em ambos os países. 


\section{Referências}

BRASIL. Ministério da Educação. Escassez de professores no Ensino Médio: propostas estruturais e emergenciais. Brasília: Câmara de Educação Básica do Conselho Nacional de Educação, 2007.

ELIAS, Norbert; SCOTSON, John L. Os estabelecidos e os outsiders. Tradução: Vera Ribeiro. Rio de Janeiro: Zahar Editor, 2000.

GATTI, Bernadete Angelina. Professores: impasses e desafios. Brasília: UNESCO, 2009.

IFPE. Plano Pedagógico do Curso de Licenciatura em Geografia. Recife: CGEO, 2013.

Comissão Própria de Avaliação do IFPE. Resultado preliminar da avaliação do Curso de Licenciatura em Geografia. Recife: 2015.

KAERCHER, Nestor. A geografia escolar não serve para quase nada, mas... In: Revista Geográfica de América Central - Número Especial EGAL, 2011- Costa Rica II Semestre 2011, p. $1-13$.

LIPOVETSKY, Gilles. O reino da hipercultura: cosmopolitismo e civilização ocidental. In: LIPOVETSKY, Gilles; JUVIN, Hervé. A globalização ocidental: controvérsia sobre a cultura planetária. Tradução: Armando Braio Ara. Barueri (SP): Manole, 2012.

MEZZADRA, Florencia. Apostar a la docencia, desafíos y posibilidades para la política educativa argentina. Buenos Aires : Fundación CIPPEC, 2014.

SANTOS, Milton. Por uma outra globalização: do pensamento único à consciência universal. $11^{\mathrm{a}}$ ed. Rio de Janeiro: Record, 2004.

ZAMERO, M. La formación docente en alfabetización como objeto de investigación. El primer estudio nacional. Buenos Aires: Instituto Nacional de Formación Docente, Ministerio de Educación de la Nación, 2010. 